\title{
Synthesis of enones, pyrazolines and pyrrolines with gem-difluoroalkyl side chains
}

\author{
Assaad Nasr El Dine ${ }^{1,2}$, Ali Khalaf ${ }^{1,2}$, Danielle Grée ${ }^{1}$, Olivier Tasseau ${ }^{1}$, \\ Fares Fares ${ }^{2}$, Nada Jaber ${ }^{2}$, Philippe Lesot ${ }^{3}$, Ali Hachem ${ }^{* 2}$ and René Grée ${ }^{* 1}$
}

\section{Letter}

\section{Address:}

${ }^{1}$ Université de Rennes 1, Institut des Sciences Chimiques de Rennes, CNRS UMR 6226, Avenue du Général Leclerc, 35042 Rennes Cedex, France, ${ }^{2}$ Laboratory for Medicinal Chemistry and Natural Products, Lebanese University, Faculty of Sciences (1) and PRASE-EDST, Hadath, Beyrouth, Lebanon and ${ }^{3}$ RMN en Milieu Orienté, ICMMO, CNRS UMR 8182, Université de Paris Sud, 91405 Orsay cedex, France

Email:

Ali Hachem* - ahachem@ul.edu.lb; René Grée* -

rene.gree@univ-rennes1.fr

* Corresponding author

Keywords:

${ }^{19} \mathrm{~F} /{ }^{1} \mathrm{H}$ HOESY; gem-difluoroalkyl derivatives; organo-fluorine compounds; palladium catalysis; pyrazolines; pyrrolines
Beilstein J. Org. Chem. 2013, 9, 1943-1948.

doi:10.3762/bjoc. 9.230

Received: 03 July 2013

Accepted: 06 September 2013

Published: 26 September 2013

This article is part of the Thematic Series "Organo-fluorine chemistry III".

Guest Editor: D. O'Hagan

(C) 2013 El Dine et al; licensee Beilstein-Institut. License and terms: see end of document.

\begin{abstract}
Starting from easily accessible gem-difluoropropargylic derivatives, a DBU-mediated isomerisation affords enones in fair yields with a gem-difluoroalkyl chain. These derivatives were used to prepare pyrazolines and pyrrolines with the desired gemdifluoroalkyl side chain by cyclocondensations in good yields and with excellent stereoselectivity. A one-pot process was also successfully developed for these sequential reactions. By carrying out various types of Pd-catalyzed coupling reactions for compounds with a $p$-bromophenyl substituent a route to focused chemical libraries was demonstrated.
\end{abstract}

\section{Introduction}

A widely used strategy in bioorganic, medicinal chemistry and in chemical biology is the selected introduction of fluorine in organic molecules since it strongly modifies their properties [1-9]. On the other hand, heterocyclic molecules - in particular, the so-called privileged scaffolds - are introduced very classically in the core of pharmaceutical products $[10,11]$. Therefore, it appears to be of much interest to design novel methodologies for the preparation of new fluorinated heterocyclic molecules. We developed a programme to investigate the preparation and uses of new propargylic fluorides [12-14], which have been employed in the synthesis of fluorinated analogues of lipids $[15,16]$ and in carbocyclic systems $[17,18]$. They have also been used for the preparation of several 5 and 6-membered heterocycles [19-22]. The goal of the present work is to demonstrate 
that selected propargylic derivatives [23-25] can be employed for the preparation of enones with a gem-difluoroalkyl chain by using an isomerisation process (Scheme 1).

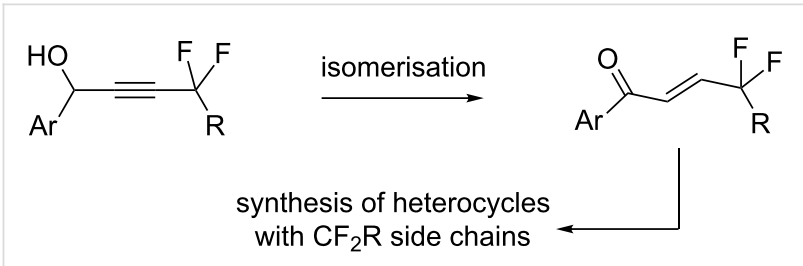

Scheme 1: Strategy towards the target molecules.

These intermediates can be employed for the preparation of representative 5-membered heterocyclic systems with $\mathrm{CF}_{2} \mathrm{R}$ side chains by using cyclocondensation reactions. Furthermore, selected molecules in these series were functionalized by using appropriate palladium-catalyzed coupling reactions en route to chemical libraries.

\section{Results and Discussion}

The first example of a base-mediated isomerisation process for an alkyne activated by an ester group was reported by Nineham and Raphael in 1949 [26]. Later, extension to other electrophilic alkynes was demonstrated by Sonye and Koide [27]. Recently, it has been established by Yamazaki's group that propargylic alcohols bearing a $\mathrm{CF}_{3}$ group on the triple bond could be isomerised to the corresponding enones. In that case, $\mathrm{Et}_{3} \mathrm{~N}$ proved to be sufficient as a catalyst to perform this transformation [28].

The required starting propargylic alcohols were obtained by a reaction of the lithium salt of easily available gem-difluoro propargylic derivative 1 [18] with aromatic aldehydes, affording compounds 2a-2e in $71-82 \%$ yields (Scheme 2 and Table 1). With these gem-difluoro intermediates, $\mathrm{Et}_{3} \mathrm{~N}$ was not an efficient catalyst since only a low conversion was observed and the reaction was not clean. On the contrary, the DBU-mediated isomerisation was successful, affording the desired enones 3a-3e in $60-63 \%$ yields. The selectivity was excellent since in all cases the $E$-isomer was obtained almost exclusively ( $>98 \%$ ). Similar reactions were carried out with propargylic derivatives bearing alkyl groups instead of the (Ar) aromatic or heteroaromatic group, but these reactions were not successful. Therefore, this reaction appears limited to derivatives with aryl or heteroaryl substituents as in the case of the $\mathrm{CF}_{3}$-substituted propargylic derivatives [28].

Next, we turned towards the preparation of heterocyclic structures from enones 3. Pyrazolines are well-recognized heterocyclic cores for pharmacologically active molecules [29].

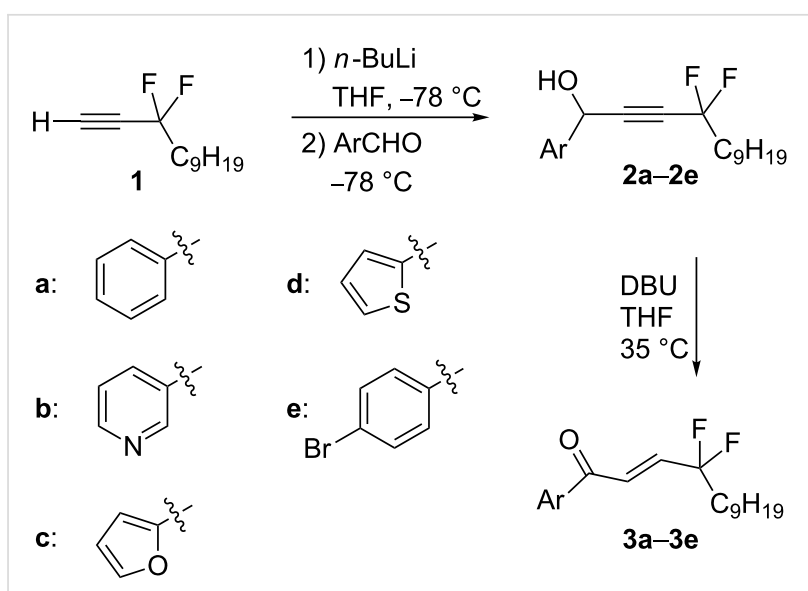

Scheme 2: Synthesis of enones with a gem-difluoroalkyl side chain.

Table 1: Synthesis of enones $\mathbf{3 a - 3 e .}$

\begin{tabular}{llll} 
Entry & $\mathrm{Ar}$ & Step 1 Yield (\%) & Step 2 Yield (\%) \\
\hline 1 & $\mathrm{Ph}$ & 2a (82) & 3a (62) \\
2 & $\mathrm{C}_{5} \mathrm{H}_{4} \mathrm{~N}$ & 2b $(78)$ & 3b $(62)$ \\
3 & $\mathrm{C}_{4} \mathrm{H}_{3} \mathrm{O}$ & 2c $(79)$ & 3c $(63)$ \\
4 & $\mathrm{C}_{4} \mathrm{H}_{3} \mathrm{~S}$ & 2d $(71)$ & 3d $(60)$ \\
5 & $p-\mathrm{PhBr}$ & 2e $(81)$ & 3e $(61)$
\end{tabular}

Therefore, they were selected as first examples of 5-membered heterocyclic targets with the fluorinated side chain. Reaction of 3a-3e with methylhydrazine gave the desired pyrazolines $\mathbf{4 a}-\mathbf{4 e}$ in $79-86 \%$ yields (Scheme 3 ).

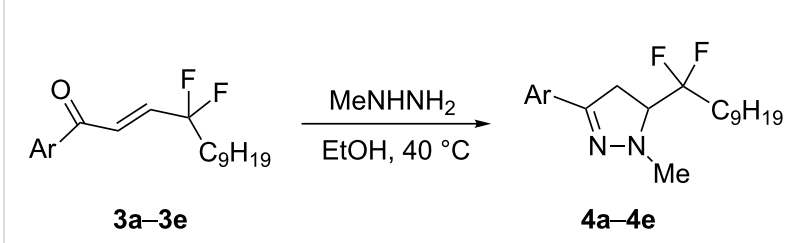

Scheme 3: Synthesis of pyrazolines with a gem-difluoro side chain.

It appeared that the reaction conditions for the synthesis of these pyrazolines were compatible with the first isomerisation step, therefore the possibility of a "one-pot" reaction was considered. Indeed, by heating a mixture of propargylic alcohols $\mathbf{2 a - 2 e}$ with DBU (1,8-diazabicycloundec-7-ene) in the presence of methylhydrazine (Scheme 4) the pyrazolines $\mathbf{4 a - 4 e}$ were obtained after $3-7 \mathrm{~h}$ in excellent yields ( $82-92 \%$, Table 2$)$. This very short and efficient synthesis of pyrazolines 4 can be related to another excellent one-pot reaction with 3-components where the first step is a Pd-catalyzed coupling-isomerisation process followed by a cyclocondensation [30]. 


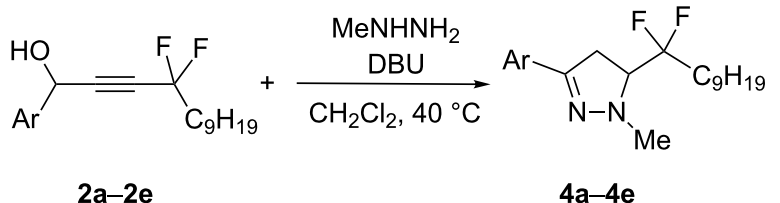

Scheme 4: One-pot synthesis of pyrazolines with a gem-difluoro side chain.

Table 2: Synthesis of pyrazolines $\mathbf{4 a - 4 e}$.

\begin{tabular}{llll} 
Entry & $\mathrm{Ar}$ & Yield (\%) (3 to 4) & Yield (\%) (1 to 4) \\
\hline 1 & $\mathrm{Ph}$ & 4a (85) & 4a (86) \\
2 & $\mathrm{C}_{5} \mathrm{H}_{4} \mathrm{~N}$ & $\mathbf{4 b}(79)$ & 4b (82) \\
3 & $\mathrm{C}_{4} \mathrm{H}_{3} \mathrm{O}$ & $\mathbf{4 c}(81)$ & 4c $(84)$ \\
4 & $\mathrm{C}_{4} \mathrm{H}_{3} \mathrm{~S}$ & $\mathbf{4 d}(82)$ & 4d $(83)$ \\
5 & $p-\mathrm{PhBr}$ & 4e $(86)$ & 4e $(92)$
\end{tabular}

Pyrroline is another noteworthy example of a heterocyclic scaffold useful in bioorganic and medicinal chemistry [31,32]. It is also well-recognized for agrochemicals, especially in combination with $\mathrm{CF}_{3}$ substituents. Recently, the group of Shibata has developed an elegant organocatalyzed asymmetric approach to such pyrrolines [33]. Moreover, an efficient synthesis of $\beta$-trifluoromethylated $\Delta^{1}$-pyrrolines has been reported [34]. Therefore, we selected pyrrolines with $\mathrm{CF}_{2} \mathrm{R}$ side chains as a second example of 5-membered heterocyclic targets. Condensation of the anion of glycine ester diphenylimine 5 with the enones $\mathbf{3 a}-\mathbf{3 e}$ afforded the desired pyrrolines $\mathbf{6 a}-\mathbf{6 e}$ (Scheme 4 and Table 3). In all cases good yields were obtained, and a complete selectivity for the trans-isomer was observed as established by
NMR analysis of the crude reaction mixtures. This is different from the results obtained by starting from enones with $\mathrm{CF}_{2} \mathrm{CF}_{2} \mathrm{X}$ side chains, where trans/cis mixtures were reported [34]. The ${ }^{3} J_{\mathrm{HH}}(6.3-6.5 \mathrm{~Hz}$, trans) of our pyrrolines were very close to those of similar molecules bearing $\mathrm{CF}_{2}-\mathrm{CF}_{3}$ chains (6.4-6.6 Hz), while for latter derivatives the cis coupling constants were larger $(\geq 8.3 \mathrm{~Hz})$ [34]. This was confirmed in the case of pyrroline $6 \mathbf{a}$ by performing additional ${ }^{19} \mathrm{~F} /{ }^{1} \mathrm{H}$ hOe $2 \mathrm{D}$ experiments which revealed strong correlations between the fluorine atoms of the $\mathrm{CF}_{2}$ group and the cyclic protons $\mathrm{H}_{\mathrm{c}}$ and $\mathrm{H}_{\mathrm{a}}$ (see Scheme 5 and 2D spectrum in the Supporting Information File 1 for details).

\begin{tabular}{|c|c|c|c|}
\hline Entry & $\mathrm{Ar}$ & Yield (\%) (3 to 6) & Yield (\%) (1 to 6$)$ \\
\hline 1 & $\mathrm{Ph}$ & $6 a(74)$ & $6 a(73)$ \\
\hline 2 & $\mathrm{C}_{5} \mathrm{H}_{4} \mathrm{~N}$ & 6b (73) & 6b (76) \\
\hline 3 & $\mathrm{C}_{4} \mathrm{H}_{3} \mathrm{O}$ & $6 c(75)$ & $6 c(73)$ \\
\hline 4 & $\mathrm{C}_{4} \mathrm{H}_{3} \mathrm{~S}$ & 6d (74) & 6d (71) \\
\hline 5 & $p-\mathrm{PhBr}$ & $6 e(78)$ & $6 e(75)$ \\
\hline
\end{tabular}

The reaction conditions were compatible with both steps and an example of a one-pot reaction was performed starting from 2a-2e. The desired pyrrolines $\mathbf{6 a - 6 e}$ were obtained in excellent yields (71-76\%, Scheme 6 and Table 3).

Another important issue was the possibility of using these molecules as scaffolds for the preparation of focused chemical libraries. In order to explore this possibility we developed representative examples of Pd-catalyzed reactions starting from p-bromo derivatives $4 \mathbf{e}$ and $\mathbf{6 e}$.

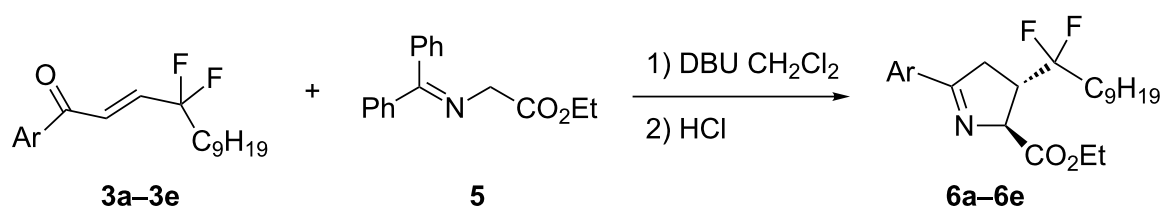

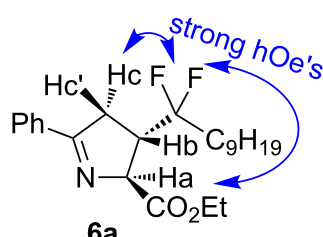

Scheme 5: Synthesis of pyrrolines with a gem-difluoro alkyl side chain.<smiles>OC(Br)C#CC(F)(F)c1ccccc1</smiles>

$2 a-2 e$<smiles>CCOC(=O)CN=C(c1ccccc1)c1ccccc1</smiles>

5

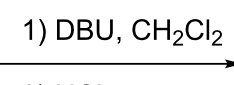

2) $\mathrm{HCl}$<smiles>CCOC(=O)C1N=C(Br)C[C@H]1C(F)(F)c1ccccc1</smiles>

$6 a-6 e$ 
The results are given in Scheme 7 for pyrazoline $4 \mathbf{e}$. Suzuki-Miyaura coupling [35] gave biphenyl derivative 7e in $82 \%$ yield, while the Heck [36] and Sonogashira [37] reactions afforded also the desired targets $8 \mathbf{e}$ and $9 e$ in $72 \%$ and $77 \%$ yield respectively. Similar results were obtained in Pd-mediated reactions starting from pyrroline $\mathbf{6 e}$, as indicated in Scheme 8 . The desired molecules $\mathbf{1 0 e}-\mathbf{1 2 e}$ were obtained in good yields.

\section{Conclusion}

In summary, we developed an efficient access to enones with gem-difluoroalkyl side chains through a base-mediated isomerisation of fluorinated propargylic alcohols. Although this method is, to date, limited to compounds with aryl or heteroaryl substituents, corresponding enones appear as versatile intermediates for the preparation of heterocyclic derivatives. This has been established through the synthesis of pyrazolines

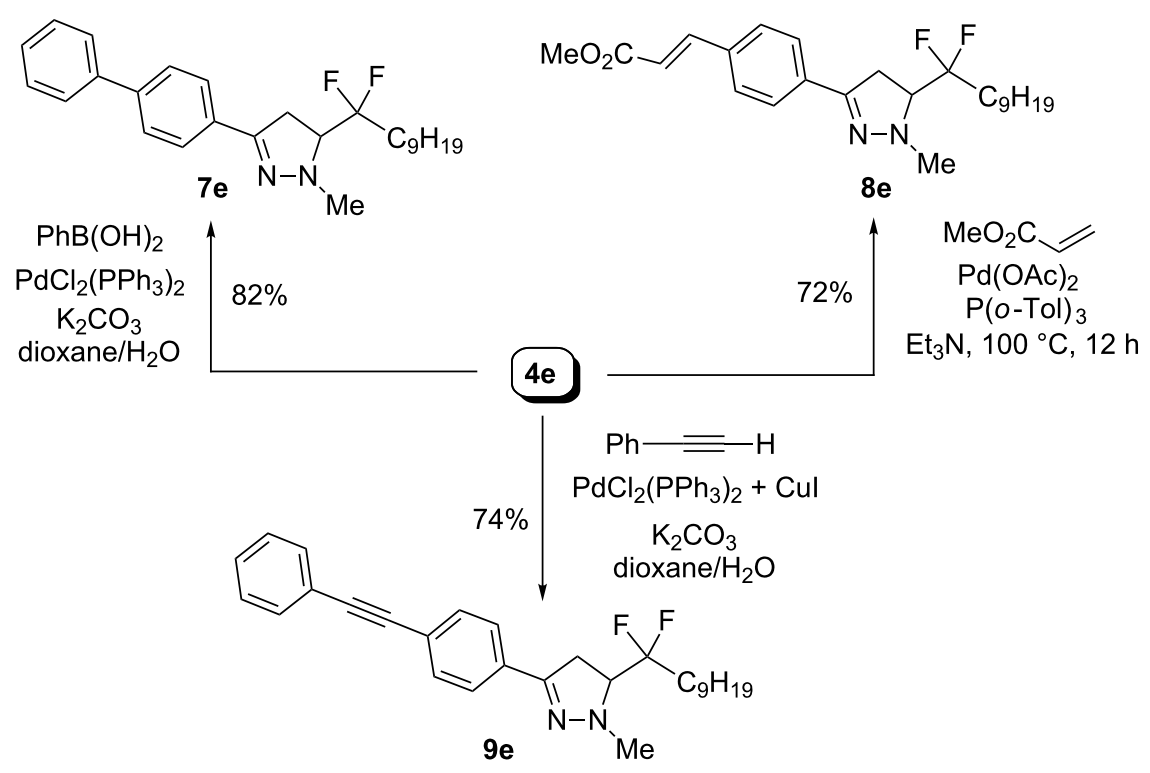

Scheme 7: Pd-catalyzed coupling reactions towards chemical libraries of pyrazolines with a gem-difluoro side chain.

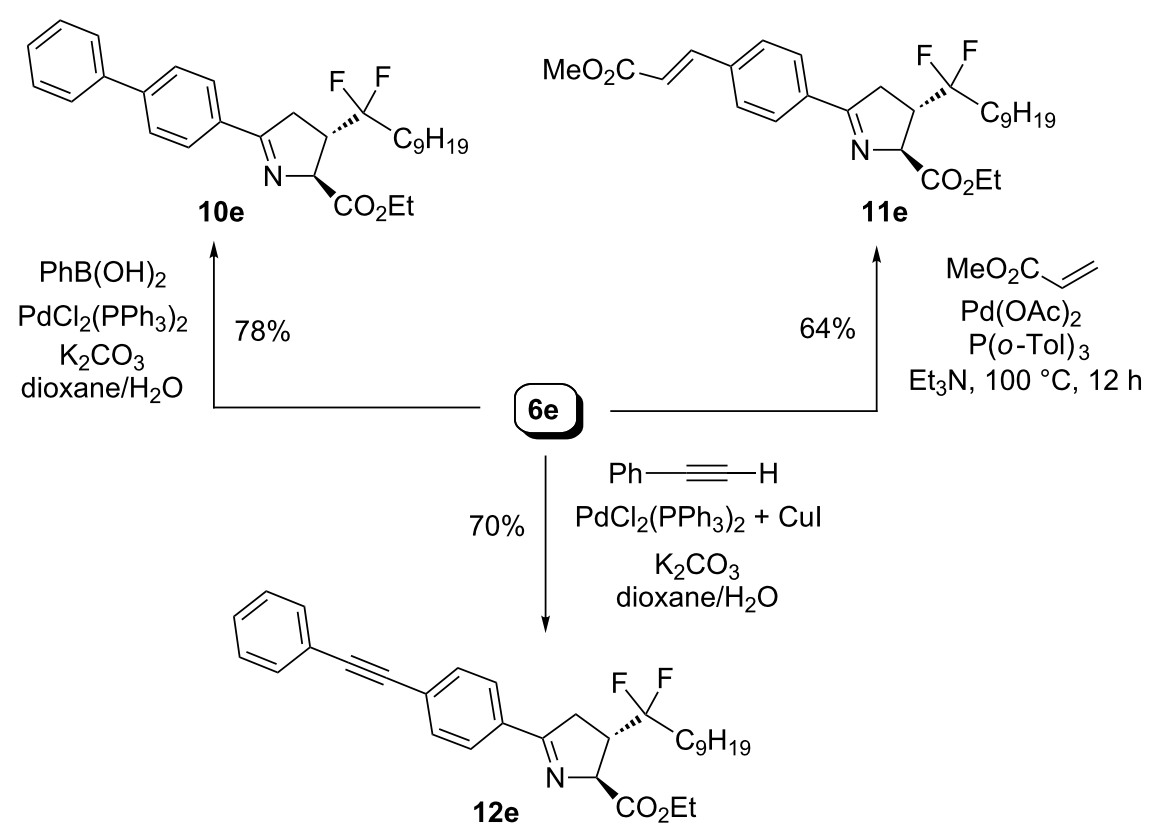


and pyrrolines with gem-difluoroalkyl side chains. With appropriate substituents, derivatives of this type can be used for the preparation of chemical libraries.

\section{Supporting Information}

\section{Supporting Information File 1}

Experimental details, NMR analysis and characterization data of new compounds.

[http://www.beilstein-journals.org/bjoc/content/ supplementary/1860-5397-9-230-S1.pdf]

\section{Acknowledgements}

We thank the CNRS and the University of Rennes 1 for financial support. We thank CRMPO (Rennes) for the mass spectral analyses.

\section{References}

1. Ojima, I.; McCarthy, J. R.; Welch, J. T., Eds. Biomedical Frontiers in Fluorine Chemistry, American Chemical Society: Washington, DC, 1996. doi:10.1021/bk-1996-0639

2. Welch, J. T.; Eswarakrishnan, S. Fluorine in Bioorganic Chemistry; Wiley-Interscience: New York, NY, USA, 1991.

3. Welch, J. T. Tetrahedron 1987, 43, 3123. doi:10.1016/S0040-4020(01)90286-8

4. Isanbor, C.; O'Hagan, D. J. Fluorine Chem. 2006, 127, 303. doi:10.1016/j.jfluchem.2006.01.011

5. Bégué, J.-P.; Bonnet-Delpon, D. J. Fluorine Chem. 2006, 127, 992. doi:10.1016/j.jluchem.2006.05.006

6. Kirk, K. L. J. Fluorine Chem. 2006, 127, 1013 doi:10.1016/j.jluchem.2006.06.007

7. Hagman, W. K. J. Med. Chem. 2008, 51, 4359. doi:10.1021/jm800219f

8. Filler, R.; Saha, R. Future Med. Chem. 2009, 1, 777. doi: $10.4155 / \mathrm{fmc} .09 .65$

9. O'Hagan, D. J. Fluorine Chem. 2010, 131, 1071. doi:10.1016/j.jfluchem.2010.03.003

10. Dolle, R. E.; Le Bourdonnec, B.; Worm, K.; Morales, G. A.; Thomas, C. J.; Zhang, W. J. Comb. Chem. 2010, 12, 765. doi:10.1021/cc100128w And references cited therein.

11. Welsh, M. E.; Snyder, S. A.; Stockwell, B. R. Curr. Opin. Chem. Biol. 2010, 14, 347. doi:10.1016/j.cbpa.2010.02.018 And references cited therein

12. Prakesch, M.; Grée, D.; Grée, R. Acc. Chem. Res. 2002, 35, 175. doi:10.1021/ar010055

13. Pacheco, M. C.; Purser, S.; Gouverneur, V. Chem. Rev. 2008, 108, 1943. doi:10.1021/cr068410e

And references cited therein. See for a comprehensive review on the chemistry of propargylic allylic fluorides

14. Prakesch, M.; Kerouredan, E.; Grée, D.; Grée, R.; DeChancie, J.; Houk, K. N. J. Fluorine Chem. 2004, 125, 537. doi:10.1016/j.jfluchem.2003.11.027

15. Manthati, V. L.; Grée, D.; Grée, R. Eur. J. Org. Chem. 2005, 3825. doi:10.1002/ejoc. 200500200
16. Manthati, V. L.; Murthy, A. S. K.; Caijo, F.; Drouin, D.; Lesot, P.; Grée, D.; Grée, R. Tetrahedron: Asymmetry 2006, 17, 2306. doi:10.1016/j.tetasy.2006.08.010 And references cited therein.

17. Grée, D.; Grée, R. Tetrahedron Lett. 2007, 48, 5435. doi:10.1016/j.tetlet.2007.06.007

18. Pujari, S. A.; Kaliappan, K. P.; Valleix, A.; Grée, D.; Grée, R. Synlett 2008, 2503. doi:10.1055/s-2008-1078179

19. Blayo, A.-L.; Le Meur, S.; Grée, D.; Grée, R. Adv. Synth. Catal. 2008, 350, 471. doi:10.1002/adsc.200700488

20. Bannwarth, P.; Valleix, A.; Grée, D.; Grée, R. J. Org. Chem. 2009, 74, 4646. doi:10.1021/jo900674u

21. Bannwarth, P.; Grée, D.; Grée, R. Tetrahedron Lett. 2010, 51, 2413. doi:10.1016/j.tetlet.2010.02.116

22. Bannwarth, P.; Grée, D.; Das, S.; Yadav, J. S.; Grée, R. J. Fluorine Chem. 2012, 134, 180. doi:10.1016/j.jluchem.2011.03.003

23. Arimitsu, S.; Fernández, B.; del Pozo, C.; Fustero, S.; Hammond, G. B. J. Org. Chem. 2008, 73, 2656. doi:10.1021/jo7025965 See for preparation of other series of fluoropropargylic derivatives by a completely different route.

24. Xu, B.; Hammond, G. B. Angew. Chem., Int. Ed. 2005, 44, 7404. doi:10.1002/anie.200502807

See for preparation of other series of fluoropropargylic derivatives by a completely different route.

25. Wang, Z. G.; Hammond, G. B. J. Org. Chem. 2000, 65, 6547. doi:10.1021/jo000832f See also references cited therein and for preparation of other series of fluoropropargylic derivatives by a completely different route.

26. Nineham, A. W.; Raphael, R. A. J. Chem. Soc. 1949, 118. doi:10.1039/jr9490000118

27. Sonye, J. P.; Koide, K. J. Org. Chem. 2007, 72, 1846. doi:10.1021/jo0623944

28. Yamazaki, T.; Kawasaki-Takasuka, T.; Furuta, A.; Sakamoto, S. Tetrahedron 2009, 65, 5945. doi:10.1016/j.tet.2009.05.087

29. Marella, A.; Ali, Md. R.; Alam, Md. T.; Saha, R.; Tanwar, O.; Akhter, M.; Shaquiquzzaman, Md.; Alam, M. M. Mini-Rev. Med. Chem. 2013, 13, 921. doi:10.2174/1389557511313060012

30. Müller, T. J. J.; Ansorge, M.; Aktah, D. Angew. Chem., Int. Ed. 2000, 39, 1253. doi:10.1002/(SICI)1521-3773(20000403)39:7<1253::AID-ANIE1253>3. $0 . \mathrm{CO} ; 2-\mathrm{X}$

31. Bellina, F.; Rossi, R. Tetrahedron 2006, 62, 7213. doi:10.1016/j.tet.2006.05.024

32. Zhang, Y.; Ran, C.; Zhou, G.; Sayre, L. M. Bioorg. Med. Chem. 2007, 15, 1868. doi:10.1016/j.bmc.2006.11.025

33. Kawai, H.; Yuan, Z.; Kitayama, T.; Tokunaga, E.; Shibata, N. Angew. Chem., Int. Ed. 2013, 52, 5575. doi:10.1002/anie.201301123

34. Marrec, O.; Christophe, C.; Billard, T.; Langlois, B.; Vors, J.-P.; Pazenoc, S. Adv. Synth. Catal. 2010, 352, 2825. doi:10.1002/adsc.201000487

35. Miyaura, N.; Suzuki, A. Chem. Rev. 1995, 95, 2457. doi:10.1021/cr00039a007

36. Heck, R. F.; Nolley, J. P., Jr. J. Org. Chem. 1972, 37, 2320. doi:10.1021/jo00979a024

37. Sonogashira, K. J. Organomet. Chem. 2002, 653, 46 doi:10.1016/S0022-328X(02)01158-0 


\section{License and Terms}

This is an Open Access article under the terms of the Creative Commons Attribution License

(http://creativecommons.org/licenses/by/2.0), which permits unrestricted use, distribution, and reproduction in any medium, provided the original work is properly cited.

The license is subject to the Beilstein Journal of Organic Chemistry terms and conditions:

(http://www.beilstein-journals.org/bjoc)

The definitive version of this article is the electronic one which can be found at:

doi:10.3762/bjoc. 9.230 